\title{
O processo de logística reversa aplicado no produto EPS (ISOPOR)
}

\author{
The reverse logistics process applied to the EPS product (ISOPOR) \\ El proceso de logística inversa aplicado al producto EPS (ISOPOR)
}

\section{Resumo}

Refletindo ao atual contexto ambiental de preservação, e de reduzam os impactos ambientais e que sejam economicamente sustentáveis, o processo de logística reversa possibilita fomentar e corroborar com os sistemas produtivos permite auxiliar no retorno de produtos pós-consumo. A logística reversa do EPS (poliestireno expandidoIsopor) ainda é precária, pois, não é economicamente atrativa para cooperativas e seus cooperados, quando comparada a outros produtos recicláveis. Porém torna-se de extrema relevância o debate sobre o tema e a visualização dos dados já apurados. Por meio da utilização da metodologia bibliográfica foi feita a partir do levantamento de referências teóricas já analisadas, com tudo o trabalho apresenta estes resultados e que ainda a muito a se fazer com a utilização do EPS no Brasil.

Palavras-chave: Logística; Reciclagem; Isopor; Meio ambiente; Logística Reversa.

\begin{abstract}
Reflecting the current environmental context of preservation, and of reducing environmental impacts and that are economically sustainable, the reverse logistics process makes it possible to foster and corroborate with the production systems, helping to return post-consumer products. The reverse logistics of EPS (expanded polystyrene - Styrofoam) is still precarious, as it is not economically attractive to cooperatives and their members, when compared to other recyclable products. However, the debate on the topic and the visualization of the data already obtained are extremely relevant. Through the use of the bibliographic methodology it was made from the survey of theoretical references already analyzed, with all the work presents these results and that there is still a lot to be done with the use of EPS in Brazil.
\end{abstract}

Keywords: Logistics; Recycling; Styrofoam; Environment; Reverse Logistics.

\section{Resumen}

Reflejando el actual contexto ambiental de preservación, y de reducción de impactos ambientales y que sean económicamente sustentables, el proceso de logística inversa permite fomentar y corroborar con los sistemas productivos, ayudando a devolver los productos post-consumo. La logística inversa del EPS (poliestireno expandido Styrofoam) sigue siendo precaria, ya que no resulta económicamente atractivo para las cooperativas y sus miembros, en comparación con otros productos reciclables. Sin embargo, el debate sobre el tema y la visualización de los datos ya obtenidos son sumamente relevantes. Mediante el uso de la metodología bibliográfica se hizo a partir del relevamiento de referencias teóricas ya analizadas, con todo el trabajo presenta estos resultados y que aún queda mucho por hacer con el uso de EPS en Brasil.

Palabras clave: Logística; Reciclaje; Poliestireno; Medio Ambiente; Logística Inversa.

\section{Introdução}

Nos dias atuais o assunto que se apresenta em destaque é relacionado a reciclagem de produtos que agridem o diretamente o meio ambiente. A percepção de que os produtos naturais são finitos e a necessidade de reutilizar é importante para uma continuidade da vida desde os pequeninos até a vida adulta.

Através deste fato, o assunto de logística reversa torna se relevante não somente para empresas mas para toda uma 
sociedade que considera necessário o planejamento e ação de controle eficiente e eficaz dos custos de produção que abrange desde o ponto de consumo até o reprocessamento, com o intuito de recompor uma parcela ou criar um valor ao produto final (Souza; Fonseca, 2008).

A indústria da reciclagem assume um papel relevante neste cenário por ser a principal responsável de melhor processamento desses recursos. Além deste papel o seguimento precisa de um apoio logístico e motivação de uma cadeia social que proporciona diversos desmembramentos dos produtos reciclados e melhor conhecimento sobre a forma de reciclar e reutilizar.

A implantação da logística reversa para a empresa proporciona um retorno econômico positivo na relação pós consumo, pois proporciona resultados financeiros nas operações industriais da empresa pelo simples fato de aproveitar os recursos secundários, que são aquele advindos de canais reversos de reciclagem ou de revalorizações mercadológicas e nos canais reversos de reuso e de remanufatura (Leite, 2009).

Esses recursos advindos desta economia proporcionam menores investimentos no setor produtivo da fábrica, proporcionando maior valor de fluxo de caixa com a comercialização dos produtos secundários e também dos resíduos provenientes de produção (Lora, 2000).

A conscientização da logística reversa para a empresa e sociedade proporciona a formação de um elo nas questões legais, ambientais e nas econômicas, o que destaca sua importância e o seu estudo no contexto organizacional. As empresas tornam se ecologicamente eficiente por meio de reciclagem (Carter; Ellram,1998), percebem retornos econômicos e vantagens competitivas (Rogers; Tibben-Lembke, 2001), além de se tornar uma empresa com imagem sustentável, fato que consolida e proporciona fidelidade a seus clientes e ganho de imagem que eleva o prestígio da marca e sua exposição no mercado para seus acionistas (Rogers; Tibben-Lembke, 1998).

\section{Referencial Teórico}

\subsection{Logística Empresarial}

Historicamente a logística nasceu da expertise de militares em abastecer-se com armamentos, munições, medicamento e alimentos, enquanto se deslocavam da sua base para outras posições em linha de batalha. A logística empresarial pode ser definida como a gestão integrada das áreas de finanças, marketing e produção dentro da empresa no curso do processo logístico (Ballou, 2006).

A logística assumia grande importância no desenvolvimento de parcerias, agregando tecnologia e tornando-se estratégica. Para a logística ser bem sucedida é necessário planejar o atendimento contínuo das necessidades dos clientes, eliminar a burocracia, demoras, inseguranças, falhas, erros, defeitos, retrabalho e todas as demais tarefas desnecessárias. A logística empresarial, estuda como a administração pode prover melhor nível de rentabilidade nos serviços de distribuição aos clientes e consumidores (Ballou, 2006)

A logística é a parte do Gerenciamento da Cadeia de Abastecimento que faz planejamento, implementações e conectase ao fluxo e armazenamento eficiente e econômico de matérias-primas, produtos semi acabados e produtos acabados, infere-se desde a sua origem até o ponto de consumo final, com o propósito de atender às exigências dos clientes (Carvalho, 2002).

Segundo o Council of Supply Chain Management Professionals (2018), o gerenciamento da logística é a parte do gerenciamento da cadeia de suprimentos que planeja, implementa e controla, de forma eficiente e eficaz, o fluxo direto e reverso e a armazenagem de bens, serviços e informações relativas desde o ponto de origem até o ponto de consumo, bem como a reciclagem, para satisfazer os requisites dos seus clientes plenamente (CSCMP, 2018).

Portanto, as atividades desenvolvidas pela logística empresarial sendo adaptadas ao contexto de sustentabilidade 
tornam-se essenciais no controle e no planejamento de ações tomadas a fim de criar mecanismos para que se permita o processo de logística reversa, permitindo assim criar e potencializar as ações de sustentabilidade e com isso faz-se necessário estudos aprofundados e discussões concernentes à temática que a cada dia se torna essencial para a nossa sobrevivência (De Oliveira Morais, 2020).

\subsection{Sustentabilidade Ambiental e as Cooperativas}

O termo sustentabilidade começou a ganhar conotação empresarial a partir da Conferência Rio-92 sobre o meio ambiente do planeta: desenvolvimento sustentável dos países e a Conferência das Nações Unidas sobre o Meio Ambiente e Desenvolvimento, realizada em junho de 1992, no Rio de Janeiro, marcou a forma como a humanidade encara sua relação com o planeta. Foi nesse momento que a comunidade política internacional admitiu que era preciso conciliar o desenvolvimento socioeconômico com a utilização dos recursos da natureza (Brasil, 1992). O mesmo movimento ocorre no que diz respeito à sustentabilidade.

Com melhor aproveitamento de seus recursos, as empresas despertam no mercado visando uma imagem de empresa sustentável (Lopes, et al, 2014). Empresas com selo sustentável certificam se com a imagem de marketing verde, fato este que desperta maior proximidade aos seus clientes.

O esgotamento dos materiais naturais destinados à produção bem como o excesso de resíduos gerados nos processos de fabricação e serviços aliados ao volume de descartes de produtos obsoletos acenderam um sinal de alerta diante das possibilidades de desastres irreversíveis. Desse modo a sustentabilidade parte da ideia de que mais do que gerar resultados econômicos, as empresas de modo geral devem gerar ações sociais e ambientais. As organizações legitimamente preocupadas coma sustentabilidade podem ser consideradas aquelas que perseguem nas suas atividades o equilíbrio entre as dimensões econômicas, social e ambiental (Barbieri; Vasconcelos;Andreassi, 2010).

Analisando o contexto de poluição dos recursos naturais, o gerenciamento de resíduos abrange a sociedade como um todo, envolvendo desde atividades individuais como a triagem e destinação correta desses resíduos, até atitudes conjuntas incentivadas pela Política Nacional de Resíduos Sólidos. Um exemplo é a implementação de acordos setoriais entre o poder público e fabricantes, importadores, distribuidores ou comerciantes para a implantação da logística reversa (Fagundes, 2015).

As cooperativas de materiais recicláveis, não apenas geram renda, mas tem importância para o desenvolvimento local sustentável, a partir de ações simples, mas de impactos profundos e que afetam estruturalmente diversos setores da sociedade. Apesar dos avanços conquistados pelo movimento da economia solidária, os empreendimentos associativos, quando observados de perto, quase sempre revelam grandes dificuldades e fragilidades ainda pouco analisadas (Soares et al.,2012; Lussari, 2016; Accorsi, 2018).

Com a minimização de recursos de produção, há a redução dos impactos ambientais provenientes daquilo que não é mais utilizado. Isto ocorre não somente pela diminuição na produção de materiais, como também porque assim evita-se sua transformação, seu transporte e a necessidade de descarte (Manzini; Vezzoli, 2016).

Considerando-se a atividade em si, e para além de indicadores meramente econômicos, pode-se dizer que um empreendimento associativo adquire condições de sustentabilidade quando os seus associados se encontram habilitados para assumir a sua condução o que é possível através do apoio dado pelos órgãos públicos e privados (Soares et al.,2012; Lussari, 2016; Accorsi, 2018).

\subsection{Logística Reversa}

A logística reversa no setor empresarial é executada através de ações onde se possibilita a recolha de materiais e 
gestão de resíduos com a finalidade de pós-processamento e reutilização dos seus itens considerando os aspectos sócios ecológicos. Todo o processo da reciclagem funciona mediante a colaboração do consumidor juntamente com as empresas dos diversos setores. A logística reversa e seu termo foram criados através do entendimento que os resíduos industriais cresceram com o incremento de produção ao longo das últimas décadas e assim preocupando os ambientalistas (Dowlatshahi, 2000).

A definição do termo logística reversa pode ser configurada como a atividade de planejamento, operações e controle dos fluxos de produtos e insumos produtivos, como também aborda as informações logísticas referentes ao processo. Como trata dos procedimentos de retorno de produtos ou ciclo produtivo, estes utilizando os canais de distribuição reversos, agregando alguns benefícios que vão desde econômico, sustentável e melhora da imagem corporativa. (Leite,2009).

Segundo Lacerda (2002), o conceito de logística reversa relaciona-se à extensão da vida dos produtos, uma vez que essa não termina na entrega ao consumidor final. Haja vista que, os produtos, quando obsoletos ou danificados retornam ao seu ponto de origem, com a finalidade de serem adequadamente separados, descartados ou até mesmo reaproveitados.

Além de perceber uma diminuição significativa em seus custos operacionais (Wang; et al, 2016), a logística reversa se apresenta como uma opção viável para a empresa para a destinação de tais resíduos (Batool; Chaudhry; Majeed, 2008), agregando valor ao resíduo reutilizado de alguma forma e de maneira barata reduzindo assim o efeito do produto original de matéria prima, proporcionando redução nos gases de efeito estufa gerados na produção de tal produto (Gregory; Kirchain, 2008).

A Lei n 12.305, de 2 de agosto de 2010, institui a Política Nacional de Resíduos Sólidos e altera a Lei $\mathrm{n}^{\circ} 9.605$, de 12 de fevereiro de 1998, em seu art. $3^{\circ}$, sendo que para os efeitos desta Lei, entende-se por Logística Reversa:

XII - logística reversa: instrumento de desenvolvimento econômico e social caracterizado por um conjunto de ações, procedimentos e meios destinados a viabilizar a coleta e a restituição dos resíduos sólidos ao setor empresarial, para reaproveitamento, em seu ciclo ou em outros ciclos produtivos, ou outra destinação final ambientalmente adequada (Brasil, 2010).

De forma prática, a Logística Reversa tem como objetivo reduzir a poluição, promover a reutilização e a reciclagem dos resíduos enquanto aprimora a marca e a imagem da organização (Nascimento et al, 2019). A Figura 1 demonstra de maneira detalhada todo o processo logístico reverso.

Figura 1: Processo Logístico Reverso.

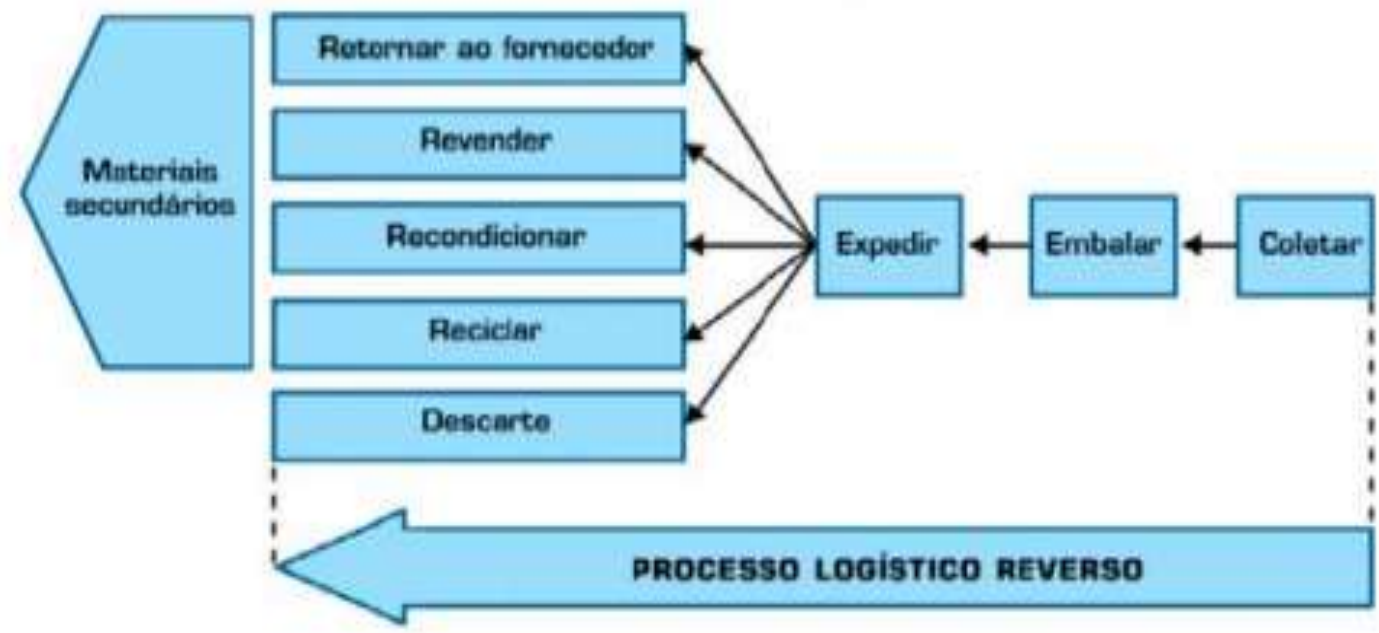

Fonte: Adaptado de Lacerda (2009). 
Um dos fatores que impulsionam a logística reversa está relacionado a aspectos econômicos e sociais. Compreender a logística reversa como fator econômico, pois permite ganhos diretos bem como reaproveitamento de materiais, redução de custos e adição de valor na recuperação e indiretos, também à antecipação a imposições legais, proteção contra a competição de mercado, imagem corporativa associada à proteção ambiental e melhora de relacionamento fornecedor/cliente (Oliveira e Almeida, 2013).

\subsection{Reciclagem do EPS (Isopor)}

O produto inicialmente estudado como objeto de logística reversa é o Poliestireno expandido (EPS), produto este que se apresenta de forma totalmente reciclado com pouca participação nos ambientes externos mas com uma característica marcante que é seu baixo peso e alto volume que se descartado de forma incorreta pode gerar grandes problemas ambientais (Leite, 2009).

O custo da reciclagem diminui com o acúmulo do produto e com as avanços tecnológicos que proporcionam um melhor aproveitamento do mesmo fazendo com que diminua a distância entre o produto virgem e o produto reciclado (Bio, 2013). O alto volume que o produto proporciona na sua unidade virgem pode ser acondicionado em um recipiente com tamanho reduzido e com espessura dura e seca dando assim aspecto novo a uma nova forma de reciclar o produto que se apresenta e criando valor para a empresa (Bio, 2013).

O EPS é um material produzido á partir de recursos limitados com uma grande tecnologia química que propicia a reciclagem deste material de uma forma que ele seja utilizado a exaustão mas que, se não for descartado de forma correta agride diretamente o meio ambiente (Kinobe et al, 2015). O símbolo de reciclagem do EPS e do XPS é o mesmo do poliestireno (PS), que utiliza o número seis envolto pelo triangulo da reciclagem, apresentado na Figura 2.

Figura 2: Simbologia da identificação do PS, EPS, XPS.

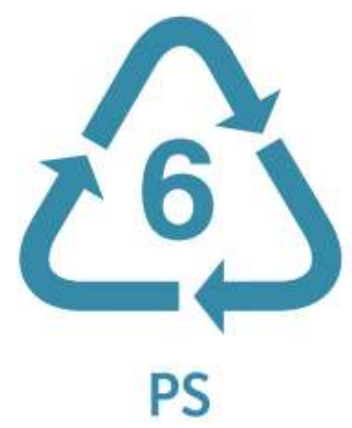

Fonte: ABRE (2016)

O produto inicialmente estudado como objeto de logística reversa é o Poliestireno expandido (EPS), produto este que se apresenta de forma totalmente reciclado com pouca participação nos ambientes externos mas com uma característica marcante que é seu baixo peso e alto volume que se descartado de forma incorreta pode gerar grandes problemas ambientais (Leite, 2009).

A legislação obrigou as empresas a mudar de postura e adotar uma forma mais consciente de reutilizar seus resíduos sólidos (Srivastava, 2008). Considerando que o EPS é um produto utilizado principalmente para transporte de produtos, as empresas de eletrônicos, que são grande utilizadoras deste produto, também se preocuparam com a melhor forma de descarte do EPS (Nagurney; Toyasaki, 2005).

Uma série de fatores influenciaram as decisões empresariais sobre a logística reversa, entre elas os fatores 
econômicos, social e de um ambiente no qual uma estratégia de mercado pode influenciar positivamente no processo de sustentabilidade.

\subsubsection{Características do EPS (Isopor)}

O EPS é um termoplástico moldado com o seu aquecimento e expandido com o poliestireno, obtêm se uma forma mais rígida e assim pode ser utilizado por diversos seguimentos da indústria.

Por ser um plástico celular rígido, sustentável, sem risco para a saúde e para o meio ambiente, o seu processo de reutilização pode ser infinito podendo até voltar a condição de matéria prima não perdendo suas propriedades mecânicas.

- 100\% reciclável e $100 \%$ atóxico;

- Possui alta densidade para ser utilizado para dar firmeza a sustentação na área da construção civil, média densidade para aplicações em produtos de eletroeletrônicos e

baixa densidade para ser utilizado como isolante térmico e para placas de papelaria;

- Seu processo de reciclagem consome poucos recursos naturais (energia e água) e gera poucos resíduos;

- Não contamina o solo, a água e o ar;

- A fabricação e utilização do EPS não geram riscos à saúde ou ao meio ambiente;

- É um material leve;

- Possui resistência ao envelhecimento, química, mecânica e umidade;

- Amortiza impactos;

- Possui versatilidade e facilidade de formatação;

- Possui fácil manipulação;

• Não causa danos à camada de ozônio;

- Fungos e bactérias não se proliferam no EPS.

\subsection{Fatores Econômicos e Sociais}

Os fatores econômicos são impulsionados também pela possibilidade de se utilizar os recursos descartados como fonte de renda para uma população sem renda direta que se utiliza deste material reciclável como única fonte de renda. Segundo Murad e Siwar, 2007, comunidades urbanas pobres e de baixa renda comprovadamente são as principais recicladoras, reutilizadoras e redutoras de seus resíduos sólidos domésticos.

Os fatores sociais são vistos que haverá um maior comprometimento da população através de políticas com foco no conhecimento e educação ambiental (Murad e Siwar, 2007). Através da conscientização e participação da população é percebido uma diminuição dos resíduos sólidos em todos os níveis sociais e segundo os mesmos autores, as comunidades urbanas pobres e de baixa renda comprovadamente se comportam de maneira consistente e favorável ao meio ambiente de gestão de resíduos sólidos ou seja, a conscientização é um fator que deverá chegar a todos os níveis sociais.

Um fato é certo, os avanços tecnológicos ajudam na reciclagem, mas não é o principal fator de melhora na sua utilização (Bio, 2013), a participação de mercado para incentivar os fabricantes e recicladores precisam estarem intimamente envolvidos com outros atores ao longo da cadeia de abastecimento que são as prefeituras, varejistas e classificadores.

\section{Metodologia}

Realizou-se uma pesquisa bibliográfica constituída por consulta a livros, dissertações, teses, revistas científicas e artigos de congressos e em bibliotecas, com o objetivo de identificar quais os pontos a serem abordados na elaboração de uma proposta de aplicação do conceito de logística reversa. 
Segundo Prodanov e Freitas (2013), a metodologia é compreendida como uma disciplina que consiste em estudar, compreender e avaliar os vários métodos disponíveis para a realização de uma pesquisa acadêmica. A Metodologia, em um nível aplicado, examina, descreve e avalia métodos e técnicas de pesquisa que possibilitam a coleta e o processamento de informações, visando ao encaminhamento e à resolução e/ou questões de investigação.

Por meio de pesquisa bibliográfica em obras que abordam o processo de logistica reversa e suas áreas, buscou-se delinear um caminho para o desenvolvimento do referido artigo.

A pesquisa bibliográfica foi feita a partir do levantamento de referências teóricas já analisadas, e publicadas por meios escritos e eletrônicos, como livros, artigos científicos, páginas de web sites (Gil, 2011).

\section{Resultados e Discussão}

A realidade da reciclagem do EPS (ISOPOR), está longe de ser a ideal no Brasil, onde isto ocorre das diversas barreiras a respeito da operacionalização da logística reversa que deve ser empregada no processo, passando também por questões de valores financeiros decorrente da baixa procura deste material nas cooperativas de reciclagem espalhadas em todo o país.

O Brasil recicla apenas aproximadamente $34 \%$ do EPS produzido, número este que vem aumentando com o passar dos anos porém ainda muito aquém do esperado conforme apresentado na Figura 3, onde são mensurados os dados entre os anos de 2008 até 2012, onde há uma lacuna sobre informações mais atualizadas. São reciclados em média 13.370 toneladas ano das 39.340 toneladas de EPS pós consumo ano, gerando assim ainda um grande campo para a geração de novos produtos a serem gerados pela reciclagem desta matéria prima.

Figura 3: Evolução da reciclagem do EPS.

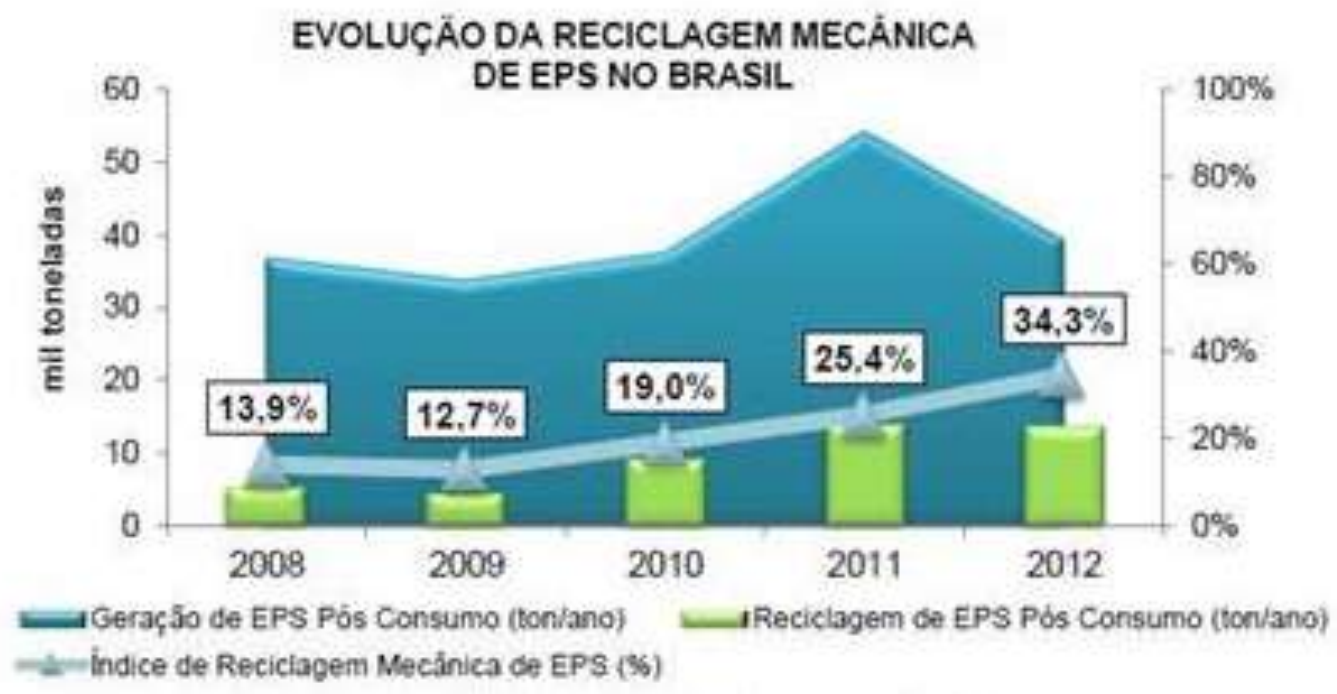

Fonte: MaxiQuim (2013)

Os dados mostram que a reciclagem do EPS pós-consumo (embalagens diversas, entre outros) tem crescido ano a ano no Brasil, o que não deixa de ser um resultado muito positivo, comparável a países desenvolvidos. Em 2008, por exemplo, o Brasil reciclava apenas $13,9 \%$ do que era descartado na época.

Também torna-se possível mensurar a produção de reciclagem do EPS por regiões, onde se torna perceptível a importância da região sudeste neste processo conforme apresentado na Figura 4 demonstrando os maiores volumes de 
produção de reciclados, sendo também condizente com a capacidade instalada para esta finalidade entre as regiões brasileiras.

Figura 4: Produção de EPS reciclado.

\section{PRODUÇÄO DE EPS RECICLADO POR REGIÃO (ANO BASE 2012)}

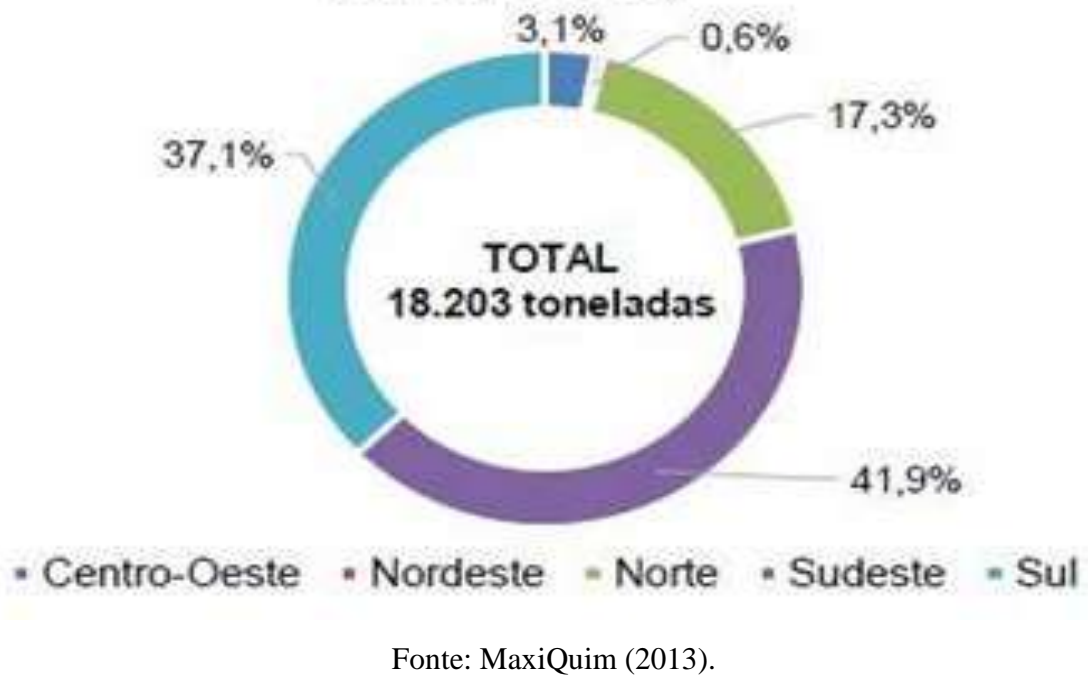

A Região Sudeste está no topo da lista de reciclagem com 41,9\% de todo o material reciclado, seguido da região sul com $37,1 \%$ em terceiro a região norte com $17,3 \%$ do material reciclado.

Outro ponto que deve ser destacado está relacionado a aplicabilidade do EPS onde a construção civil é o maior mercado para o EPS reciclado, com cerca de $80 \%$ do material produzido podendo ser (misturado em argamassa, concreto leve, lajotas, telhas termoacústicas, rodapés e decks de piscinas).

Este produto reciclado também pode ter a sua aplicação na indústria de calçados (solados, chinelos), móveis (preenchimento de puffs, por exemplo), na fabricação de utilidades domésticas (vasos de flor, floreiras, molduras de quadro), entre outros produtos, conforme apresentados no Quadro 1.

Quadro 1: Aplicações para o EPS.

\begin{tabular}{|c|c|c|c|}
\hline SEGMEKTO DE MERCADO & APLICACOES & $\begin{array}{l}\text { VocuME } \\
\text { (toneladas) }\end{array}$ & (6) \\
\hline Construçäo Civil & $\begin{array}{l}\text { Argamassa, concreto leve, lajotas, } \\
\text { telhas termo acusticas, rodapes. }\end{array}$ & 5.603 & $81 \%$ \\
\hline Móveis & $\begin{array}{l}\text { Puffs, enchimento de bancos, } \\
\text { mesas. }\end{array}$ & 484 & $7 \%$ \\
\hline Utilidades Domésticas & $\begin{array}{l}\text { Vaso de flores, fioreiras, moiduras } \\
\text { de quadros }\end{array}$ & 380 & $5,5 \%$ \\
\hline Calçados & Solados, chinelos. & 380 & $5,5 \%$ \\
\hline Outros & $\begin{array}{l}\text { Embalagens para proteção de } \\
\text { objetos. }\end{array}$ & 69 & $1 \%$ \\
\hline TOTAL & & 6.917 & $100 \%$ \\
\hline
\end{tabular}

Fonte: MaxiQuim (2013). 
O Quadro 1 apresenta algumas das possibilidades da aplicação do EPS bem como o percentual utilizado em cada um dos segmentos propostos, permitindo uma visão ampliada deste produto.

O processo de fluxo reverso do EPS não é diferente da forma que se apresenta os demais produtos recicláveis, algumas particularidades se apresentam no momento que o reciclável é deteriorado pelo processo de decomposição.

O processo de reciclagem do EPS compreende etapas que é objetivada para o seguimento industrial se deseja direcionar o reciclado. Como matéria prima, o EPS pode ser utilizado em molduras, rodapés, perfis para construção cível além de retornar a sua forma original.

Sua transformação inicia na coleta do produto em alto volume que será, além de selecionado, decomposto em pequenas partículas que a retirada do ar presente no produto, que equivale a $98 \%$ do seu volume, forma uma estrutura de baixo volume, peso e fácil manuseio. Dessa forma, sua transformação continuará para o fim do processo de fusão simples que se observa o formato original do produto com um volume significativamente baixo. A Figura 5 abaixo ilustra o processo de reciclagem do produto.

Figura 5: Processo de reciclagem do EPS.

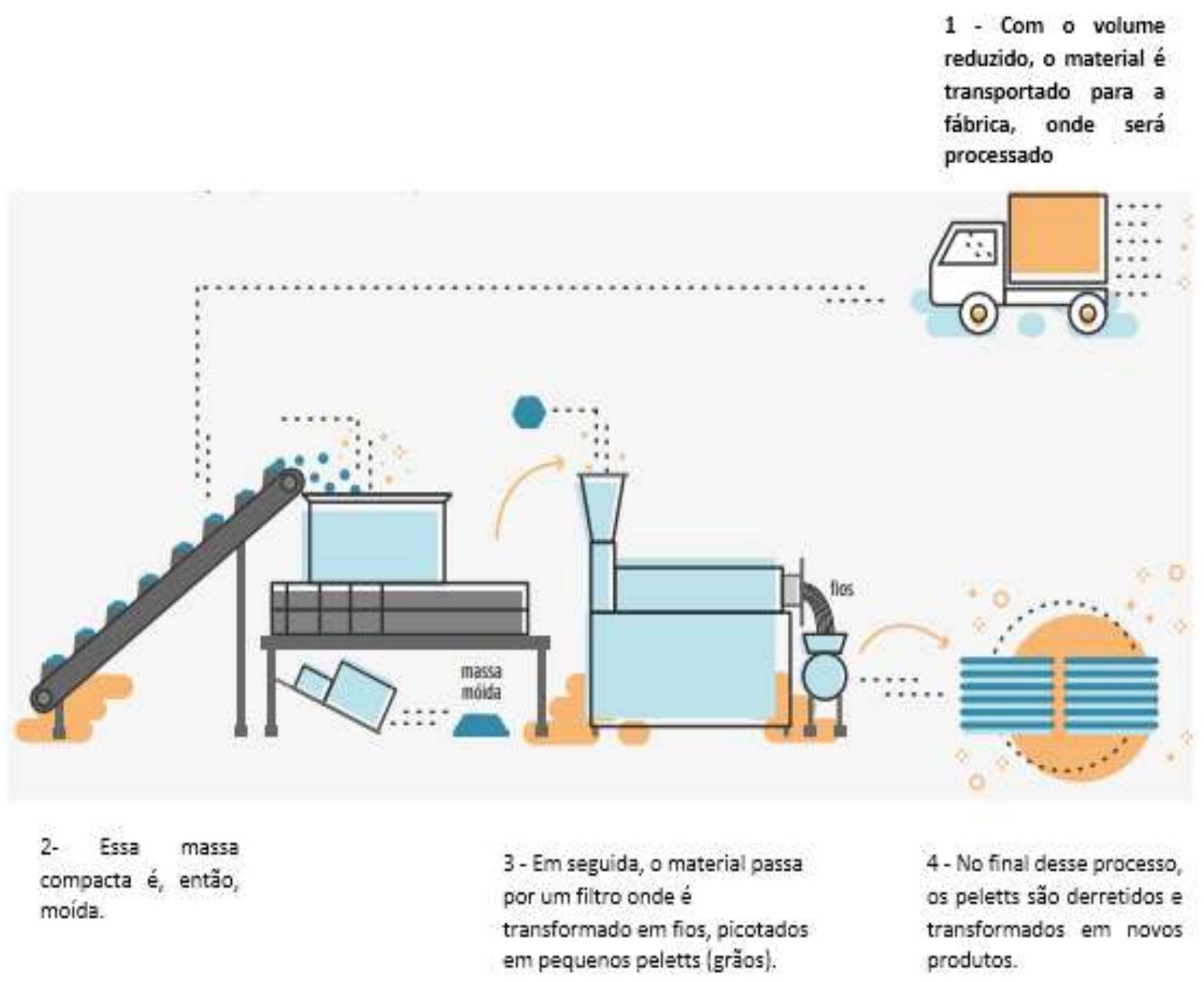

Fonte: Adaptado de MaxiQuim (2013).

As vantagens que o processo proporciona aos recicladores são grandes. O produto reciclado é competitivo na área de construção civil, utilizado em grande escala pelo setor de transporte de alimento além de ser o principal agente de transporte 
dos produtos da linha branca.

Os desafios para a reciclagem do EPS são grandes e precisam de uma atuação maior por parte do governo como forma de incentivo. Os impostos são considerados altos exigindo uma desoneração tributária para estimular a reciclagem, fato que hoje estimula a compra do produto virgem, por parte da indústria.

Por ser um reciclável que demanda elevado investimento em tecnologia e equipamentos industriais, a sua reciclagem necessita de uma produção em escala para atingir um nível adequado de custo e se tornar inviável.

\section{Conclusão}

Buscou-se neste artigo trazer informações e ampliar o conhecimento acerca do processo de logística reversa aplicado ao isopor com ênfase na conscientização da população e compreendendo como as organizações e as pessoas que fabricam e utilizam esse material atuam, medindo como a sociedade faz uso desse material e destacando as possibilidades e benefícios do poliestireno expandido possui.

Por não se tratar de um produto muito conhecido porém de pouco valor financeiro na sua revenda, torna-se um tema relevante pela quantidade de informações que podem ser apresentadas para o público, oferecendo orientação sobre a maneira correta de descartar tal material, possibilitando uma maior prevenção quanto as questões ambientais tão importante para a sociedade como um todo.

Certamente, este é o caminho para uma melhor sustentabilidade ambiental e financeira, mas ainda há um longo percurso pela frente. Porém o sucesso dependerá da conscientização e união dos esforços de todos os envolvidos em todas as esferas sejam elas do poder público, setor produtivo e população uma vez que somente com a participação de todos e alinhamento dos investimentos será possível ampliar as questões de reciclagem do EPS.

Verificou-se ainda que existe uma falta de divulgação e incentivos devido ao baixo preço pago por quilograma de EPS para o processo de reciclagem, e com isso representa um grande desafio no setor de reciclagem deste produto, pois existe um grande volume em contrapartida um baixo peso o que desestimula a comercialização do reaproveitamento por grande parte da sociedade.

\subsection{Trabalhos futuros}

$\checkmark$ Realizar a comparação dos indices de reciclagem do EPS com os índices de recilcagem do alumínio.

$\checkmark$ Identificar quais os segmentos da indústria que mais utilizam o EPS na sua composição e como se dá o processo reverso.

\section{Agradecimentos}

Aos nossos familiares pelo apoio, carinho e compreensão.

\section{Referências}

ABRE (2016) - Associação Brasileira de Embalagem. Simbologia técnica brasileira de identificação de materiais. Obtido em: https://www.abre.org.br/dadosdo-setor/ano2016/

Accorsi, R. J. M. (2018). Avaliação de sustentabilidade em cooperativas de reciclagem de Porto Alegre/RS.

Ballou, R. H. (2009). Gerenciamento da Cadeia de Suprimentos-: Logística Empresarial. Bookman Editora.

Barbieri, J. C., Vasconcelos, I. F. G. D., Andreassi, T., \& Vasconcelos, F. C. D. (2010). Inovação e sustentabilidade: novos modelos e proposições. Revista de Administração de Empresas, 50(2), 146-154. 
Batool, S. A., Chaudhry, N., \& Majeed, K. (2008). Economic potential of recycling business in Lahore, Pakistan. Waste management, $28(2), 294-298$.

Bio, I. (2013). Study on an increased mechanical recycling target for plastics. Final Report prepared for Plastic Recyclers Europe, sl: BIO Inteligence Service.

BRASIL - Senado Federal - Conferência Rio-92 sobre o meio ambiente do planeta: desenvolvimento sustentável dos países. Obtido em: http://www.senado.gov.br/noticias/Jornal/emdiscussao/rio20/a-rio20/conferencia-rio-92-sobre-o-meio-ambiente-do-planeta-desenvolvimento-sustentaveldospaises.aspx

Carter, C. R., \& Ellram, L. M. (1998). Reverse logistics: a review of the literature and framework for future investigation. Journal of business logistics, 19(1), 85 .

de Carvalho, J. M. C., \& Cardoso, E. G. (2002). Logística. Sílabo.

de Oliveira Morais, M., Brejão, A. S., Silva, U. J., \& Neto, J. S. (2020). Dez anos da política nacional de resíduos sólidos: um estudo comparativo entre 2011 e 2020 sobre o entendimento dos consumidores referente ao descarte de equipamentos eletroeletrônicos. Brazilian Journal of Development, 6(11), 91851-91873.

de Oliveira, L. G., \& de Almeida, M. L. (2013). Logística reversa de embalagens como estratégia sustentável para redução de custos: um estudo em uma engarrafadora de bebidas/Reverse logistics of packaging as a sustainable strategy for cost reduction: a study in a bottler beverages. Revista Metropolitana de Sustentabilidade (ISSN 2318-3233), 3(2), 78-98.

Dowlatshahi, S. (2000). Developing a theory of reverse logistics. Interfaces, 30(3), 143-155.

Fagundes, A. B. (2015). Modelagem fuzzy para avaliação de desempenho ambiental do gerenciamento de resíduos sólidos industriais.

Gil, A. C. (2000). Metodologia Do Ensino Superior . Editora Atlas SA.

Gregory, J. R., \& Kirchain, R. E. (2008). A framework for evaluating the economic performance of recycling systems: a case study of North American electronics recycling systems.

Junior, M. A. D. C. S., de Souza Pinho, V., Carneiro, S. N. V., \& Bernal, C. C. (2012). Sustentabilidade e desenvolvimento local: o caso da Cooperativa ÓLimpo. Revista Expressão Católica, 1(2).

Kinobe, J. R., Gebresenbet, G., Niwagaba, C. B., \& Vinnerås, B. (2015). Reverse logistics system and recycling potential at a landfill: A case study from Kampala City. Waste Management, 42, 82-92.

Lacerda, L. (2002). Logística reversa: uma visão sobre os conceitos básicos e as práticas operacionais. Rio de Janeiro: COPPEAD/UFRJ, 6.

Leite, P. R. (2003). Logística reversa. Pearson. São Paulo.

Lopes, V. N., \& Pacagnan, M. N. (2014). Marketing verde e práticas socioambientais nas indústrias do Paraná. Revista de Administração, 49(1), 116-128.

Lora, E. E. S. (2000). Prevenção e controle da poluição nos setores Energético. Industrial e.

Lussari, W. R. (2016). Grupo de apoiadores e cooperlix em Presidente Prudente-SP, Brasil: modelo e evolução de suas relações durante quinze anos.

Manzini, E., \& Vezzoli, C. A. (2002). O desenvolvimento de produtos sustentáveis. Os requisitos ambientais dos produtos industriais (pp. 89-345). Edusp.

MaxiQuim (2013) - Indice_Reciclagem.pdf Obtido em: http:// www.plastivida.org.br/images/releases/ Release_092_. Método Científico cap2 Novo Hamburgo.

Murad, W., \& Siwar, C. (2007). Waste management and recycling practices of the urban poor: a case study in Kuala Lumpur city, Malaysia. Waste management \& research, 25(1), 3-13.

Nagurney, A., \& Toyasaki, F. (2005). Reverse supply chain management and electronic waste recycling: a multitiered network equilibrium framework for ecycling. Transportation Research Part E: Logistics and Transportation Review, 41(1), 1-28.

Nascimento, M. C., dos Santos, M. A., \& Ferreira, G. S. A. (2019). A LOGÍSTICA REVERSA E OS FATORES SOCIOAMBIENTAIS E ECONÔMICOS. SITEFA-Simpósio de Tecnologia da Fatec Sertãozinho, 2(1), 343-353.

Nguyen, L. (2018). Improving Sutchi catfish supply chain in An Giang, Vietnam.

Rogers, D. S., \& Tibben-Lembke, R. (2001). An examination of reverse logistics practices. Journal of business logistics, 22(2), $129-148$.

Souza, S. F.; \& Fonseca, S. U. L. (2008). Logística reversa: oportunidades para redução de custos em decorrência da evolução do fator ecológico. In: SEMINÁRIO EM ADMINISTRAÇÃO, 11; São Paulo, 2008, FEA USP. http://www.ead.fea.usp.br/Semead/11semead/resultado/an_resumo.asp?cod_trabalho=87>

Srivastava, S. K. (2008). Network design for reverse logistics. Omega, 36(4), 535-548.

Tibben-Lembke, R. S., \& Rogers, D. S. (1998). Differences between forward and reverse logistics in a retail environment. Supply Chain Management: An International Journal.

Wang, Q., Li, J., Yan, H., \& Zhu, S. X. (2016). Optimal remanufacturing strategies in name-your-own-price auctions with limited capacity. International Journal of Production Economics, 181, 113-129. 